\title{
ARTIKELEN
}

\section{Preventie en de aanpak van radicaliseren en terrorisme: een herziening}

\author{
Carl H.D. Steinmetz
}

\begin{abstract}
Ongeveer de helft (54\%) van de Nederlandse GGZ-instellingen heeft patiënten die radicaliseren. Deze kraamkamer van radicale verliezers verdient meer aandacht. Dat lukt alleen als de GGZ uit het vastgelopen discours treedt dat radicaliseren geen stoornis is. Een voedingsbodem van deze en andere kraamkamers zijn, naast sociale en psychologische invloeden, grieven over sociale, economische en gezondheidsongelijkheden, opvattingen over het buitenlands beleid (Bhui et al., 2014), en ook de oorlogen die jaarlijks vanaf 1798 door de Verenigde Staten worden geïnitieerd, al dan niet met hulp van het Verenigd Koninkrijk, de Europese Unie en dus ook Nederland (Middelkoop, 2018). In dit artikel wordt gepleit om 'vuur niet met vuur' te bestrijden. Gepleit wordt voor het toepassen van 'Activisme van de Hoop' (Lleshi, 2018) dat eigen grootvaders kent, zoals Martin Luther King, Mahatma Gandhi en Nelson Mandela. Tot slot wordt voor alle onderwijs- en hulpverleningsinstellingen een handelingsperspectief aangedragen voor de aanpak van jonge mensen in de tumultueuze fase van de adolescentie.
\end{abstract}

Mahatma Gandhi zei: 'Met onvrede kun je geen vrede kweken. Dat is tussen doornen naar druiven zoeken. Nederigheid heelt wonden, arrogantie verergert ze' (Gandhi, 2017). Deze les in preventie kan mogelijk door de GGZ, wijkteams, welzijnsorganisaties, politie, veiligheidskundigen en lokale gemeentepolitici worden omarmd bij de aanpak van radicaliseren en terrorisme door gemeenten (steden en dorpen). Juist het tegendeel doet opgeld. Voortdurend worden oudbakken opvattingen en feiten over radicaliseren en terrorisme te berde gebracht waardoor nieuwe wonden ontstaan of bij oude wonden de korsten worden opengereten; dit laatste treft vooral moslims in Nederland (Aharouay, 2018).

Dit betoog over een preventieve aanpak van radicaliseren en terrorisme dat noopt tot nederigheid, leunt op een aantal sleutelbronnen. Allereerst een onderzoek waarover is gerapporteerd in 'Niets is wat het lijkt. Patronen van bedrog' (Middelkoop, 2018), dat mogelijk heeft geleid tot de opmaat van de 'Radicale Verliezer' (Van Buren, 2016). In de tweede plaats onderzoeksgegevens waaruit valt af te leiden dat de GGZ een verwaarloosde kraamkamer is van 'Radicale verliezers'. Het ministerie van VWS stelde een openbaar rapport over dit onderzoek bij alle Nederlandse GGZ-instellingen naar de aanpak van radicaliseren en terrorisme en de (recentste) aanslagen in Nederland niet op prijs. In de derde plaats een enquête (Bhui et al., 2014) die is afgenomen in twee Engelse steden bij vrouwen en mannen tussen de 18-45 jaar met een moslimachtergrond voor wie een vra- 
genlijst is ontwikkeld die SyfoR heet. In deze vragenlijst zijn onder meer vragen opgenomen over het oordeel van de ondervraagden over Engelse troepen die zijn afgereisd naar Irak en Afghanistan en verder een oordeel over het tegen deze troepen vechten. In de vierde plaats een review over Europese jongeren waaruit blijkt dat de psychopathologische uitingen bij adolescenten vele gelijkenissen vertonen met mechanismen gedurende het proces van radicaliseren (Campelo et al., 2018).

De oproep van Mahatma Gandhi tot nederigheid en het onderhavige betoog nopen tot een herziening van de preventielessen die worden uitgedragen door instanties die binnen de context van Nederlandse gemeenten zich inzetten voor de aanpak van radicaliseren en terrorisme. $\mathrm{Nu}$ worden Nederlandse gemeenten op hun wenken bediend door het actieprogramma Integrale aanpak Jihadisme van het NCTV ${ }^{1}$ (waaronder handreikingen gemaakt, een 'Rijksopleidingsinstituut tegengaan Radicaliseren’ opgericht en een Informatieportaal).

\section{Feiten over radicaliseren en terrorisme volgens de Nederlandse overheid}

'Radicalisering is een proces dat sommige mensen kunnen doormaken waarin ze zich steeds meer afkeren van de samenleving en zo radicaal worden dat zij bereid zijn om grenzen te overschrijden om zo hun doelen te bereiken. Extreem daarbij is het gebruik van geweld, maar ook in de fasen daarvoor kunnen er problemen ontstaan, zoals intimiderend gedrag richting bepaalde groepen of het verkondigen van extreme ideeën.' (Bakker et al., 2016: 75)

'Terrorisme is een angstopwekkende methode van herhaaldelijke, gewelddadige actie, ingezet door (semi)clandestiene, individuele groepen of statelijke actoren, om idiosyncratische, criminele of politieke redenen, waarbij, anders dan bij moordaanslagen, de directe doelwitten van het geweld niet de belangrijkste doelwitten zijn.' (Bakker et al., 2016: 23)

Kortom, terrorisme is vanuit ideologische motieven dreigen met, voorbereiden of plegen van op mensen gericht ernstig geweld, dan wel daden gericht op maatschappij ontwrichtende zaakschade, met als doel maatschappelijke veranderingen bewerkstellingen, de bevolking ernstige vrees aanjagen of politieke besluitvorming beïnvloeden.'

Het NCTV (2016-2020) zegt over de feiten:

'De terroristische dreiging in Europa kwam in de periode 2011-2015 niet alleen vanuit jihadistische, maar ook vanuit extreemrechtse hoek. De angst voor immigranten, de islam en aanslagen heeft in diverse Europese landen bijgedragen aan de groei van extreemrechts. Extreemrechtse groepen en individuen pleegden gewelddaden tegen vluchtelingen, opvanglocaties en moslims. Ook in Nederland. Als reactie hierop is ook extreemlinks in Nederland weer actiever geworden. Zij zoeken de confrontatie met anti-islam- en anti- 
asielgroepen. Met de Nederlandse alt right beweging en Erkenbrand is het antisemitisme in extreemrechtse kringen weer terug van (nooit helemaal) weggeweest.' (NCTV, 2018a)

Het NCTV benadrukt wederom: 'De rechts-extremistische en rechts-terroristische dreiging kan de nationale veiligheid ondermijnen omdat het in potentie de sociale en politieke stabiliteit kan bedreigen en de fysieke veiligheid van Nederlanders (doden en gewonden) in gevaar kan brengen.' (NCTV, 2018b).

Bij overheidspublicaties over radicaliseren en terrorisme ontbreken aantallen incidenten, vandaar dat hier met een inschatting van het totaal aantal incidenten gerekend wordt via een lokaal voorbeeld. Butler (2014) zegt dat het meldpunt radicalisering van Amsterdam in 201332 meldingen en adviesaanvragen heeft verwerkt'. Het Parool (2017) zegt: 'In Amsterdam lopen 47 jongeren rond die “zorgelijk radicaal” gedrag vertonen: 37 jongens en tien meisjes.' In Amsterdam (Amsterdam, 2012) loopt het aantal meldingen en registraties van radicaliseren en dreiging van terrorisme na 2006-2007 terug. In totaal kwamen er 184 meldingen (gemiddeld twee per maand) binnen bij het gemeentelijk Amsterdams melden adviespunt; bij een derde hiervan is sprake van serieuze radicalisering. Het officiële aantal Amsterdamse meldingen van radicaliseren en dreiging van terrorisme is dus lager dan waar Butler (2014) en Het Parool (2017) mee zijn gekomen. Om te kunnen extrapoleren wordt gewerkt met het laagste getal dat hierboven staat vermeld, twee meldingen van serieuze radicalisering per maand, kortom een conservatieve schatting van de werkelijkheid. Stel nu dat de officiële Amsterdamse (totaalaantal inwoners in 2018 is 854.047) meldingen geëxtrapoleerd worden naar Nederland als geheel (totaalaantal inwoners in 2018 is 17,2 miljoen), dan is het maximumaantal geschatte meldingen van radicaliseren en dreiging van terrorisme in Nederland 483 per jaar. Bij 161 meldingen is er dan sprake van serieuze radicalisering. Als de veronderstelling klopt dat radicaliseren en terrorisme vooral een stadsprobleem is, dan is dit aantal eerder lager dan hoger.

\section{Oorlogen, aanslagen, radicale verliezers en het ontbreken van activisten}

De Verenigde Staten voeren volgens Middelkoop et al. (2018) vanaf $1798 \mathrm{t} / \mathrm{m}$ 2017 buiten de eigen landsgrenzen 255 militaire interventies en oorlogen uit, minimaal één militaire interventie/oorlog per jaar. Het Amerikaanse ministerie van Defensie noemt deze oorlogen 'preventief. Verder interveniëren de Verenigde Staten tussen 1946 en 200081 maal in verkiezingen van andere landen. Voor 9/11 lag er een notitie van het Amerikaanse ministerie van Defensie waarin staat dat de Verenigde Staten van plan zijn binnen vijf jaar zeven landen uit te schakelen (Middelkoop et al., 2018: 162): Irak, Syrië, Libanon, Libië, Somalië, Soedan en afsluitend Iran. Voor 9/11 plande de regering-Bush een interventie tegen Irak met als doel Sadam Hoessein van zijn troon te stoten. Aan het einde van de jaren tachtig zochten de Verenigde Staten naar een goed excuus om in het Midden-Oosten een Amerikaanse troepenmacht te stationeren. De belangrijkste 
redenen voor deze militaire interventies, oorlogen en beïnvloedingen van verkiezingen zijn bescherming van Amerikaanse olie- en gasbelangen, het handhaven van de dollar als wereldbetaalmiddel, Rusland, China en Frankrijk geen toegang geven tot de 'gas- en olie'-bodemschatten in het Midden-Oosten en kunnen beschikken over een blanco check om bovengenoemde oorlogen te kunnen voeren.

Vanaf 1942 tot heden voert Amerika oorlog in bijna alle moslimlanden in NoordAfrika. Dat begon in 1942 met een Amerikaanse invasie in Algerije en Marokko. Deze oorlogen gaan gepaard met miljoenen vluchtelingen, gewonden en doden met als gevolg dat Noord-Afrikanen van boven de Sahara de Verenigde Staten niet beschouwen als een bevriende natie.

Hoewel Noord-Afrika vanaf 2010 een Arabische lente ${ }^{2}$ achter de rug heeft en een Hirak-opstand in de Rif (Akarkach, 2018), is in Noord-Afrika nog geen Mahatma Gandhi opgestaan die zich geweldloos verzet tegen Amerikaanse, Saoedische, Russische, Turkse en Europese oorlogsinterventies in hun landen. Vandaar dat nog steeds vuur met vuur en bommen met bommen worden bestreden. Oog om oog, tand om tand is het Noord-Afrikaanse motto. Intussen zijn vanaf 1913 veel moslims uit Noord-Afrika naar Europa geëmigreerd: in de Eerste en Tweede Wereldoorlog als soldaat of als arbeider in de mijnindustrie, vanaf de jaren zestig als gastarbeider en recent als vluchteling (vooral inwoners uit Syrië).

Het ontbreken van een Mahatma Gandhi in Noord-Afrika en het Westen kan leiden tot 'radicale verliezers'. Van Buren (2016) stelt een paradigmashift voor en noemt personen die radicaliseren en terroristische handelingen plegen 'radicale verliezers'. Volgens Van Buren (2010) zijn:

'radicale verliezers niet het product van de onderklasse maar van mensen die door benadeling in de ruimste zin van het woord buiten de boot vallen, terwijl het anderen goed gaat. Uit de boot vallen wordt geschraagd door het intuïtieve inzicht van radicale verliezers dat Amerikanen het op hen hebben gemunt. Omdat de wens tot erkenning en verandering geen grenzen kent, valt de ene radicale verliezer voor de lokroep van het kalifaat, gaat de andere op in criminele liquidaties, maakt weer een ander van een bewindspersoon, gezagsdrager of instituut zijn/haar object van haat of keert zich tegen de samenleving als geheel.'

Op deze plaats is de vraag gerechtvaardigd of deze systemische jaarlijkse Amerikaanse oorlogen en die van hun bondgenoten daadwerkelijk radicale verliezers opleveren. Zicht op het antwoord op deze vraag is terug te vinden in het onderzoek van Bhui et al. (2014). Deze enquête gaat over sympathie van moslims (vooral mannen en vrouwen die oorspronkelijk afkomstig zijn uit Pakistan en

2 De Arabische Lente (Arabisch: الربيع العربسي, ar-rabīi al-`arabī) is een golf van opstanden, protesten en revoluties in de Arabische wereld die begon op 18 december 2010 en bestaat uit revoluties in Tunesië, Egypte, Libië en Jemen, een burgeroorlog in Syrië, grote demonstraties en protesten in Bahrein, protesten van middelgrote schaal in Jordanië, Marokko, Algerije, Irak, Oman en de Palestijnse gebieden en incidentele protesten in Mauritanië, Saoedi-Arabië, Soedan, Libanon en Koeweit. Alleen in Qatar en in de Verenigde Arabische Emiraten zijn geen incidenten gemeld. 
Bangladesh) voor gewelddadig protest en terrorisme in Oost-London en Bradford. Dit onderzoek laat positieve correlaties $(R=0.21$ en 0.23$)$ zien tussen aan de ene kant het gebruik van geweld, dreigen met terroristische aanslagen (ook om onrechtvaardigheid te bestrijden, en eigen ras en religie te beschermen) en aan de andere kant Engelsen die vechten in Irak of Afghanistan. Met andere woorden: hoewel indirect is via dit Engelse onderzoek de hypothese aannemelijker geworden dat Amerikaanse oorlogen en die van hun bondgenoten radicale verliezers opleveren.

\section{De GGZ als kraamkamer van radicale verliezers}

Na de jihadistische moord op Theo van Gogh (2 november 2004) nemen aanslagen (Bakker et al., 2016) op moskeeën en islamitische scholen, zoals de Bedirschool, in Uden toe. Volgens Van der Valk ${ }^{3}$ en de database van De Koning zijn moskeeën tussen 2005 en 2010117 maal doelwit van geweld geweest. Dit beeld correspondeert met de bevindingen uit een Canadese grootschalige internationale enquête (Cauchy, 2015). Ook in 2017 bevestigt de toenmalige Nationaal Coördinator Terrorismebestrijding en Veiligheid Schoof het beeld dat het Nederlandse dreigingsniveau substantieel is vanwege mogelijke jihadistische of ISIS-aanslagen en een Europese trend van aanslagen door rechts- en linksradicalen.

De recente drie 'terroristische' aanslagen in Den Haag en Amsterdam, veertien jaar na de aanslag op Theo van Gogh, staan volop in de belangstelling. Allereerst overweegt de familie van de 31-jarige Haagse Syrische ex-patiënt van de GGZinstelling Parnassia die op 5 mei 2018 drie willekeurige mensen neerstak, om aangifte te doen tegen deze GGZ-instelling omdat de familie haar meerdere malen zou hebben gewaarschuwd. Een trigger voor dit plotselinge geweld is mogelijk de afgewezen gezinshereniging in 2015 met zijn vader, die vervolgens zelf de Middellandse Zee overstak en door verdrinking om het leven kwam. In Italië heeft hij zijn vader geïdentificeerd. Volgens het Openbaar Ministerie ${ }^{4}$ had de politie al in maart 2018 een waarschuwing ontvangen dat deze man mogelijk een terroristische daad zou plegen. In de tweede plaats verwondt een 19-jarige Afghaan uit Duitsland op 3 september 2018 op het Amsterdamse Centraal Station met een mes twee Amerikaanse toeristen met als terroristisch motief 'dat in Nederland "de profeet Mohammed, de Koran, de islam en Allah" veelvuldig worden beledigd'. In de derde plaats is een 26-jarige Pakistaan op 28 augustus 2018 in Den Haag opgepakt omdat hij Wilders op Facebook met de dood heeft bedreigd. Wilders, die in de Tweede Kamer een cartoonwedstrijd over de profeet Mohammed uitschreef. Kortom, bij drie van deze meest recente aanslagplegers speelt het in diskrediet brengen van de islam een rol, bij een van de drie zou psychiatrie een rol spelen. Los hiervan is recent een groep mannen opgepakt die van plan waren een aanslag te plegen. De Volkskrant (28 september 2018) zegt hierover:

3 www.republiekallochtonie.nl/blog/opinie/update-lijst-met-incidenten-rond-moskeen.

4 https://nos.nl/artikel/2231995-haagse-politie-werd-gewaarschuwd-dat-syrier-een-aanslag-zou-

plegen.html. 
'De politie heeft met de aanhouding van zeven mannen mogelijk een grote terroristische aanslag in Nederland voorkomen. Volgens het Openbaar Ministerie $(\mathrm{OM})$ waren de verdachten vergevorderd met het plannen van een aanslag op een grootschalig evenement. De belangrijkste verdachte is een 34-jarige man uit Arnhem, die eerder is veroordeeld voor een poging tot uitreizen naar IS-gebied.'

De aanpak van radicaliseren en terrorisme is een industrie (de geplande rijksuitgaven voor contraterrorisme en nationaal veiligheidsbeleid ${ }^{5}$ voor 2020 zijn $€ 266,427$ miljoen). Veel aandacht gaat daarbij uit naar beïnvloedbare kraamkamers van jeugdige radicale verliezers. De belangrijkste kraamkamers zijn scholen, heilige huizen, informeel moskee-onderwijs (NRC, 10 september 20196) en buurthuizen (Steinmetz, 2015). Buiten beeld gebleven is de Nederlandse GGZ als kraamkamer voor jeugdige radicale verliezers. Dat zou wel eens veroorzaakt kunnen zijn door de opdracht die de maatschappij de GGZ geeft, namelijk die van stoornisbehandelaar, wat haaks staat op de behandeling van de radicale verliezer. Volgens Dom (2017) is voor het behandelen van personen die radicaliseren, geen stoornisonderbouwing te vinden. Dit beeld werd bevestigd door een gezelschap van psychiaters en psychologen uit de regio Amsterdam (Steinmetz, 2015). Vandaar dat het ministerie van VWS en het NCTV, Arkin de opdracht hebben gegeven om hier onderzoek naar te doen.

De belangrijkste resultaten van dat onderzoek (Steinmetz, 2020) staan hieronder. De sleutelvraag in dit onderzoek was: 'Hebben GGZ-instellingen patiënten die radicaliseren? Zo ja, welk deel ${ }^{7}$ van de patiënten is dat dan?'. Van de 65 GGZinstellingen in Nederland heeft $57 \%^{8}$ aan het onderzoek ${ }^{9}$ meegedaan, totaal 37 GGZ-instellingen.

De belangrijkste uitkomsten over de aanpak van radicaliseren en terrorisme (lees 'terrorisme' hier als een intentie om een terroristische aanslag te plegen) door GGZ-instellingen in Nederland staan hieronder opgesomd:

1 vier van de 37 GGZ-instellingen hebben een signaleringsinstrument;

2 drie van de 37 GGZ-instellingen hebben een risicotaxatie-instrument;

3 vijf van de 37 GGZ-instellingen hebben een zorg/behandelplan voor cliënten die radicaliseren en/of terroriseren;

4 één van de 37 GGZ-instellingen heeft behandelrichtlijnen voor radicaliseren en/of terrorisme;

5 twee van de 37 GGZ-instellingen hebben een systeemaanpak voor personen die of radicaliseren of terroriseren;

6 geen van de 37 GGZ-instellingen heeft een screener om radicaliseren en/of terrorisme te constateren;

5 Kamerstukken II 2019/20, 35300 VI, 1, p. 3.

6 www.nrc.nl/nieuws/2019/09/10/salafistische-scholen-leren-kinderen-zich-af-te-keren-vannederland-a3972845.

7 Antwoordcategorieën waren: geen antwoord, 0-10\%, 11-20\%, 21-30\%, enzovoort.

8 Motieven om niet mee te doen zijn: dit onderwerp past niet bij mijn bedrijfsfilosofie, ik heb hier geen tijd voor en het past niet bij mijn geloof.

$9 \quad$ Het verzamelen van gegevens vond plaats in de periode december 2016 tot 1 maart 2017. 
7 geen van de GGZ-instellingen beschikt over een privacyprocedure voor radicaliseren en terrorisme;

8 zes (17\%) van de 37 GGZ-instellingen hebben trainingen verzorgd of laten verzorgen over radicaliseren en terrorisme;

9 dertien (35\%) van de 37 GGZ-instellingen hebben gebruikgemaakt van de mogelijkheid om opmerkingen te maken. De kern is: 'We zijn net gestart met dit onderwerp, het zou deel moeten uitmaken van andere vormen van agressie, radicaliseren en terrorisme mag niet geïsoleerd worden van andere vormen van extreem gedrag, het komt bijna niet voor, eerst zien we stoornissen ... daarom valt radicaliseren en terrorisme minder op en wel is er belangstelling voor cultureel bewust en sensitief behandelen'.

Van de 21 GGZ-instellingen (57\%) van de in totaal 37 GGZ-instellingen die of radicaliseren of terrorisme aanpakken, hebben negen GGZ-instellingen (9/21 = $43 \%$ ) één of meer instrumenten, zoals een signaleringsinstrument of een risicotaxatie-instrument. Van deze negen hebben zes GGZ-instellingen vier tot negen instrumenten.

\subsection{Beleidsnotities}

Drie van de zeven GGZ-instellingen die terrorisme zeggen aan te pakken, hebben een beleidsnotitie over de aanpak van de intentie van een patiënt om een terroristische aanslag te plegen. Drie van de tien GGZ-instellingen hebben een beleidsnotitie over de aanpak van patiënten die radicaliseren. In totaal hebben twee GGZinstellingen een beleidsplan voor de aanpak van terrorisme en die van radicaliseren. Van de negen GGZ-instellingen die zich bezighouden met 'all inclusive multiculturalisme' (een organisatiemodel dat past bij de inrichting van werk in de Nieuwe Wereld), hebben er twee een beleidsnotitie. Van de 28 GGZ-instellingen die zich niet bezighouden met het organiseren van all inclusive multiculturalisme heeft er één een beleidsnotitie over de aanpak van all inclusive multiculturalisme. Van de 23 instellingen die zich bezighouden met cultureel bewust en sensitief behandelen, hebben er drie een beleidsnotitie.

\subsection{Schatting van het aantal patiënten dat radicaliseert}

$54 \%$ van deze GGZ-instellingen heeft patiënten die radicaliseren. In totaal had Nederland (Markscan GGZ, 2016) in 2014863.788 patiënten in de GGZ (niet meegenomen in deze berekening is de POH-GGZ omdat huisartsen niet in het bovenstaande onderzoek zaten). Stel dat ongeveer $0,5 \%$ (het interval is tussen $0-10 \%)$ van alle patiënten in de Nederlandse GGZ radicaliseert, dan levert dat een geschat aantal op van 4.319 patiënten die op jaarbasis in Nederland radicaliseren. Een conservatieve rekensom doet dus vermoeden dat de Nederlandse GGZ enkele duizenden patiënten herbergt die radicaliseren. Twee vijfde van deze GGZ-instellingen pakt radicaliseren en terrorisme aan. Populaire interventies zijn trainingen en cultureel en sensitief behandelen. De 'aanpakkers' bevinden zich vooral in de Randstad.

De vigerende conclusie onder psychiaters dat de aanpak in de GGZ van radicaliseren en de dreiging om een terroristische aanslag te plegen, een onderlegger van 
stoornissen nodig heeft, kan worden betwist. Harde onderbouwingen voor dat betwisten worden allereerst aangetroffen in het onderzoek van Broeren (Sarma, 2016) die in Den Haag een 'forward record check' uitvoert die laat zien dat $60 \%$ van de personen die volgens de Haagse politie radicaliseren, terug te vinden is in elektronische patiëntendossiers van de Parnassiagroep (de grootste Nederlandse GGZ). Een vergelijkbare onderbouwing wordt in de tweede plaats gevonden door Weenink (2015) die stelt dat zijn 'voorlopige resultaten aangeven, dat personen met een geschiedenis van gedragsproblemen en aandoeningen oververtegenwoordigd zijn in politiebestanden van personen die radicaliseren'.

- Aangrijpingspunten voor interventies bij Europese jongeren die radicaliseren Campelo et al. (2018) pleiten ervoor dat de GGZ gerichte interventies in de jongerenkraamkamers van de GGZ in praktijk brengt om vervolgens die kennis ter beschikking te stellen aan heilige huizen, buurthuizen, wijkteams en welzijnsinstellingen. Dit pleidooi is geënt op een stevige review en metanalyse. De praktische interventies kunnen worden afgeleid van het veelomvattende model dat in deze review wordt gepresenteerd, met een drietal niveaus waarmee radicaliseren onder jonge Europeanen wordt verklaard.

'Het eerste niveau zijn individuele risicofactoren, zoals psychologische kwetsbaarheden, w.o. jeugdige ervaringen met in de steek gelaten worden, waargenomen onrechtvaardigheid en persoonlijke onzekerheid. Het tweede niveau zijn micro-omgevingsrisicofactoren, zoals het disfunctioneren van de Grootfamilie en bevriend zijn met personen die geradicaliseerd zijn. Het derde niveau zijn maatschappelijke risicofactoren, zoals geopolitieke gebeurtenissen en maatschappelijke veranderingen die gekenmerkt worden door anomalie.'

(Zie ook de paragraaf over Amerikaanse oorlogen van de Verenigde Staten.) Zie voor een verheldering figuur 1.

Concreet geven de auteurs van deze review aan dat er een sterke gelijkenis is tussen psychopathologische manifestaties van adolescentie en de mechanismen die op het spel staan bij het proces van radicaliseren.'

- Handreikingen voor Nederlandse gemeenten die radicaliseren en de intentie om een aanslag te plegen, willen aanpakken

In dit artikel wordt het door Van Buuren gemunte begrip 'radicale verliezer' geïntroduceerd. Dit zijn jongeren die uit de boot vallen en radicaliseren. Enkele handreikingen voor het voorkomen van radicaliseren en de intentie om een aanslag te plegen door 'radicale verliezers', die mogelijk bruikbaar zijn voor Nederlandse gemeenten, komen hier aan bod.

Allereerst is dat het bestrijden van anti-islampopulisme, achterstelling, discriminatie en uitsluiting (Steinmetz, 2018). Een mogelijke voedingsbodem voor het populisme bij jonge immigranten en vluchtelingen zijn oorlogen die de Verenigde 


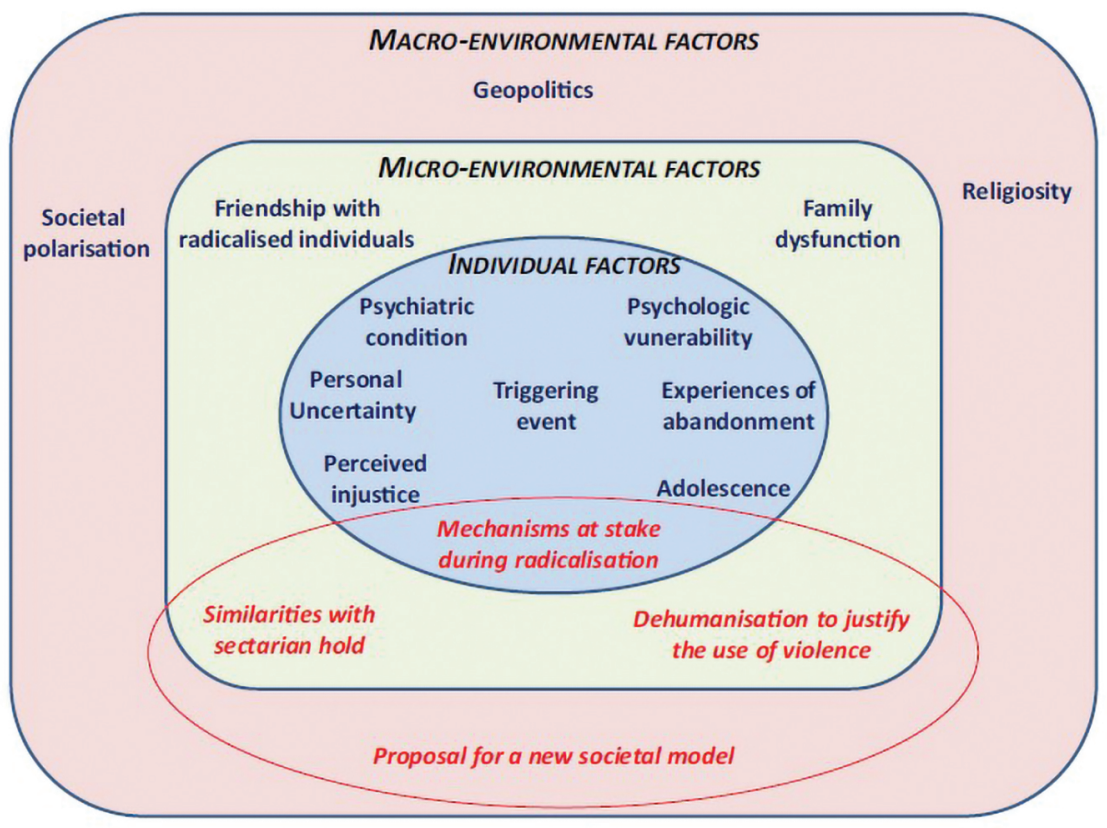

(bron: Campelo et al., 2018: 11)

\section{Figuur 1 Risk factors of Radicalisation among European Youth}

Staten vanaf 1942 in Noord-Afrika voert, deels met de steun van de Europese Unie, het Verenigd Koninkrijk, Frankrijk, Nederland, Rusland, Turkije en SaoediArabië. De gevolgen van deze oorlogen zijn immens, afgaand op het aantal vluchtelingen, gewonden en doden. Nederlandse gemeenten en de instellingen binnen de grenzen van deze gemeenten, zoals buurthuizen, scholen, wijkteams, welzijnsinstellingen en GGZ-instellingen, kunnen zich van die Nederlandse inzet door de regering distantiëren. Dit wordt burgerlijke ongehoorzaamheid genoemd.

In de tweede plaats komen moslimburgers van deze gemeenten - zeker in superdiverse steden en randstad - dagelijks in aanraking met de gevolgen van deze militaire interventies. Dat doet pijn. Om die pijn te verzachten kunnen gemeenten en de gemeentelijke instellingen de boodschappen van Mahatma Gandhi, Martin Luther King en Nelson Mandela en dichter bij huis het 'Activisme van de hoop' van Lleshi (2018) van nederigheid in acht nemen. De kern daarvan is: erkennen dat Noord-Afrikaanse moslimlanden geteisterd worden door Amerikaanse, Russische, Turkse en deels Engelse-Nederlandse-Europese oorlogen en andere militaire interventies. Benadrukken dat de oplossing niet is: vuur met vuur en bommen met bommen bestrijden. Met andere woorden, stimuleren dat gezocht wordt naar een geweldloze aanpak van dit onrecht tegenover moslims en de islam. Dat lukt door 'Activisme van de hoop' te introduceren. 
De sleutel voor een derde handreiking voor preventie ligt bij de GGZ en andere formele en informele zorginstellingen die met jongeren werken. De Nederlandse gemeenten en daar werkzame instellingen zouden hun pijlen voor de aanpak van radicaliseren, gewelddadig verzet en de intentie om een aanslag te plegen kunnen richten op de kraamkamers van de 'radicale verliezers', de personen die terecht radicaliseren maar nog niet hebben begrepen dat geweld door aanslagen te plegen of te strijden in oorlogsgebieden geen oplossing is. Een kraamkamer die lokaal beter aan bod moet komen, is de GGZ (zowel de jongeren- als volwassen-GGZ). De GGZ kan daarbij leunen op de bij hen beschikbare kennis over de psychopathologische manifestaties van adolescentie.

\section{Literatuur}

Aharouay, L. (2018) Het is politiek correct om moslims te bashen. NRC 24 mei 2018. www.nrc.nl/nieuws/2018/05/24/het-is-politiek-correct-om-moslims-te-bashena1604030.

Akarkach, B. (red.) (2018) Opstand in de Rif. Antwerpen: Uitgeverij EPO.

Bakker, E. \& J. de Roy van Zuijdewijn (2016) Terrorisme (Serie Elementaire deeltjes, nr. 20). Amsterdam: Amsterdam University Press.

Bhui, K., N. Warfa \& E. Jones (2014) Is Violent Radicalisation Associated with Poverty, Migration, Poor Self-Reported Health and Common Mental Disorders? Plos One, 9(3), e90718. doi:10.1371/journal.pone.0090718.

Butler, E. (2014) Doet Amsterdam genoeg om radicaliseren tegen te gaan? www.republiekallochtonie.nl/blog/opinie/doet-amsterdam-genoeg-om-radicaliseringtegen-te-gaan .

Buren, J. van (2016) Radicale verliezers en de noodzaak tot ontschotten. Justitiële verkenningen, 42(2). doi: 10.5553/JV/016758502016042002001.

Cauchy, D. (2015) Preventing radicalisation A systematic review. International Centre for the Prevention of Crime. www.cipc-icpc.org .

Campelo, N., A. Oppetit, F. Neau \& D. Cohen (2018). Who are the European youth willing to engage in radicalisation? A multidisciplinary review of their psychological and social profiles. European Psychiatry, 52, 1-14, http://dx.doi.org/10.1016/j.eurpsy. 2018.03.001.

Dom, G. (2017) Radicalisering, terrorisme en psychiatrie: een alternatieve waarheid? Tijdschrift voor Psychiatrie, 59(3), 136-138.

Gandhi, A. (2017) Het boek van wijsheid. 11 levenslessen van mijn grootvader, Mahatma Gandhi. Amsterdam: Harper Collins.

Gemeente Amsterdam, bestuursdienst (2012) Openbare samenvatting van Rapportage Aanpak terrorisme en radicalisering 2004-2011.

Lleshi, B. (2018) De kracht van hoop. Antwerpen: Uitgeverij EPO.

Middelkoop, W. \& T. Dollee (2018) Niets is wat het lijkt. Patronen van bedrog. Amsterdam: Amsterdam University Press.

Nationale Contraterrorisme Strategie: 2016-2020, p. 26.

NCTV 2018a (maart 2018) Dreigingsbeeld Terrorisme Nederland, 47.

NCTV 2018b (november 2018) De golfbewegingen van rechts-extremistisch geweld in WestEuropa. Aard, ernst en omvang van de rechts-extremistische geweldsdreiging in WestEuropa, inclusief Nederland. 
Unen, D. van (2017) Amsterdamse jongeren radicaliseren zorgwekkend. Het Parool 13 januari 2017.

Sarma, K.M. (2016) Understanding Terrorism: Research of relevance to Health and Social Care Professionals. Presentation World Psychiatric Associations Taskforce on: Social Divisions \& Extremist Violence: gangs, cults, terrorists, and violent offending. 25th-26th October 2016, at Queen Mary University of London, UK.

Steinmetz, C.H.D. (2015) Psychiatrie en radicaliseren: GGZ Amsterdam. ResearchGate. doi: 10.13140/RG.2.1.1627.9921.

Steinmetz, C.H.D. (2016) Radicaliseren voorkomen: Nu of Nooit. Maatwerk vakblad voor professionals in sociaal werk , 14-17.

Steinmetz, C.H.D. (2018) Immigratiebeleid: Voorkom discriminatie, uitsluiting en polarisatie. Bevorder inclusie. ResearchGate. doi: 10.1007/s41196-018-0101-z.

Steinmetz, C.H.D. (2020) Tackling radicalisation and terrorism in Dutch mental health institutions: outcomes of a Dutch population survey. In: K. Bhui \& B. Dinesh (red.), Titel, Oxford: Oxford University Press. Te verschijnen in 2020.

Weenink, A.W. (2015) Behavioural problems and disorders among radicals in police files. Perspectives on terrorism, 9(2). 